\title{
Extracellular lipids of Camelina sativa: Characterization of chloroform-extractable waxes from aerial and subterranean surfaces
}

\author{
Fakhria M. Razeq ${ }^{a}$, Dylan K. Kosma ${ }^{\mathrm{b}}$, Owen Rowland ${ }^{\mathrm{a}^{*}}$, and Isabel Molina ${ }^{\mathrm{c},{ }^{*}}$ \\ ${ }^{\mathrm{a}}$ Department of Biology and Institute of Biochemistry, Carleton University, Ottawa, \\ Ontario, Canada \\ ${ }^{\mathrm{b}}$ Department of Plant Biology, Michigan State University, East Lansing, Michigan, USA \\ ${ }^{\circ}$ Department of Biology, Algoma University, Sault Ste. Marie, Ontario, Canada
}

${ }^{*}$ Co-corresponding Authors.

Addresses:

Department of Biology, Essar Convergence Centre, Algoma University, 1520 Queen Street East, Sault Ste. Marie, Ontario, P6A 2G4, Canada. Tel.: +1 (705) 949-2301 x1078, Fax: (705) 949-6583. E-mail: isabel.molina@algomau.ca

Department of Biology, Nesbitt Building, Carleton University, 1125 Colonel By Drive, Ottawa, ON, K1S 5B6, Tel.: +1 (613) 520-2600 x4213, Fax: (613) 520-3539. E-mail: owen.rowland@carleton.ca 


\section{Abstract}

Camelina sativa (L.) Crantz is an emerging low input, stress tolerant crop with seed oil composition suitable for biofuel and bioproduct production. The chemical compositions and ultrastructural features of surface waxes from C. sativa aerial cuticles, seeds, and roots were analyzed using gas chromatography and microscopy. Alkanes, primary fatty alcohols, and free fatty acids were common components of all analyzed organs. A particular feature of leaf waxes was the presence of alkyl esters of long-chain fatty acids and very long-chain fatty alcohols, ranging from $\mathrm{C}_{38}$ to $\mathrm{C}_{50}$ and dominated by $\mathrm{C}_{42}, \mathrm{C}_{44}$ and $\mathrm{C}_{46}$ homologues. Stem waxes were mainly composed of non-sterol pentacyclic triterpenes. Flowers accumulated significant amounts of methyl-branched iso-alkanes $\left(\mathrm{C}_{29}\right.$ and $\mathrm{C}_{31}$ total carbon number) in addition to straight-chain alkanes. Seed waxes were mostly primary fatty alcohols of up to 32 carbons in length and unbranched $\mathrm{C}_{29}$ and $\mathrm{C}_{31}$ alkanes. The total amount of identified wax components extracted by rapid chloroform dipping of roots was $280 \mu \mathrm{g} \mathrm{g}^{-1}$ (fresh weight), and included alkyl hydroxycinammates, predominantly alkyl coumarates and alkyl caffeates. This study provides qualitative and quantitative information on the waxes of $C$. sativa root, shoot, and seed boundary tissues, allowing the relative activities of wax biosynthetic pathways in each respective plant organ to be assessed. This detailed description of the protective surface waxes of $C$. sativa may provide insights into its drought-tolerant and pathogenresistant properties, and also identifies $C$. sativa as a potential source of renewable highvalue natural products. 


\section{Keywords}

Camelina sativa, cuticle, seed, root, waxes, triterpenoids, alkyl hydroxycinnamates, gas chromatography, mass spectrometry, scanning electron microscopy 


\section{Introduction}

Camelina sativa (L.) Crantz, also known as 'false flax' or 'gold of pleasure', is an oilseed crop of the Brassicaceae family. It is native to south-eastern Europe and southwestern Asia and has been cultivated for its oil and fibre since ancient times (Bouby, 1998). It is cultivated today on a small scale for the health food market as its oil is rich in $\omega-3$ fatty acid ( $\alpha$-linolenic acid) and its protein-rich seed meal can be used for animal feed (Colombini et al., 2013; Putnam et al., 1993). There is considerable recent interest in developing $C$. sativa as a biofuel and high-value chemical production crop, especially on the Great Plains of North America (Iskandarov et al., 2014). C. sativa has a relatively short growth cycle (85-100 days to maturity) and is easily transformed by Agrobacterium tumefaciens (Lu and Kang, 2008). There have also been recent advances in the genomics of $C$. sativa, including large-scale gene sequencing and transcriptomic studies (Liang et al., 2013; Mudalkar et al., 2014; Nguyen et al., 2013). C. sativa is thus a good plant for basic research studies as well as for translation to field applications using genetically engineered varieties.

The advantages of $C$. sativa as a biofuel and bioproduct crop plant are its low input costs and ability to grow on marginal agricultural lands (Iskandarov et al., 2014; Putnam et al., 1993). C. sativa is frost-tolerant and requires less water and fertilizer than other oilseed crops such as Canola (Brassica napus) (Iskandarov et al., 2014). It also has a relatively high level of resistance to insect pests and plant pathogens that negatively affect other Brassicaceae crops (Francis and Warwick, 2009). These traits, as well as its short growing cycle, allow $C$. sativa to be grown on lands that are not currently used for food crops or in double cropping systems with $C$. sativa sown in late fall or early spring followed by another crop such as wheat or soybean. The mechanism(s) behind the 
stress-tolerant attributes of $C$. sativa, and whether they can be further improved, are currently unclear.

All land plants have aliphatic and phenolic-based barriers present at environmental interfaces that serve to protect them against water loss and various stresses. Their aerial surfaces are coated with a cuticle, which is comprised of cutin and waxes (Samuels et al., 2008). Cutin is a polymer mostly made up of glycerol and long-chain (C16 and C18) fatty acid derivatives overlaying the cell wall and serves as the structural backbone of the cuticle. Cuticular waxes are mixtures of low polarity compounds, including very-longchain $(\geq C 20)$ straight-chain aliphatics (e.g. fatty acids, fatty aldehydes, alkanes, primary and secondary fatty alcohols, wax esters, and $\beta$-diketones), triterpenoids, and phenoliclipids (e.g. alkylrescorcinols) (von Wettstein-Knowles, 2012). Intracuticular waxes are embedded in the cutin matrix and epicuticular waxes, often in the form of crystals, cover the outer surface. Cuticular waxes serve the essential function of limiting non-stomatal water loss (Riederer and Schreiber, 2001; Vogg et al., 2004). Epicuticular waxes being in direct contact with the environment play key roles in plant-insect and plant-pathogen interactions as well as in the shedding of dust, spores, and water droplets (Kerstiens, 1996). Cuticular wax composition varies substantially between species, organs of the same plant, developmental stages and environmental conditions (Jetter et al., 2006). Another hydrophobic surface barrier is suberin. Similar to cutin, suberin is a polyester of glycerol, phenolics and fatty acid derivatives (long-chain and very-long-chain) (Franke and Schreiber, 2007). Suberin is found on the inner face of cell walls of certain tissue layers, for example the root endodermis and peridermis. There are also waxes associated with suberin, and when in roots termed root waxes (Espelie et al., 1980; Kosma et al., 2012; Li et al., 2007). Suberin-associated or root wax compounds variably include long-chain and very-long-chain fatty acids, primary fatty alcohols, alkanes, 
monoacyglycerols, sterols, and alkyl hydroxycinnamates (fatty alcohols esterified with coumaric, caffeic, or ferulic acids) (Kosma et al., 2012).

The surface waxes of $C$. sativa may confer, in part, its relative tolerance to various abiotic and biotic stresses. These extracellular lipids may also represent an additional source of high-value components that can be extracted from the plant. We present here a detailed chemical description of the extracellular waxes of $C$. sativa aerial and root organs.

\section{Results and Discussion}

Wax mixtures from stems, leaves, flowers, seeds and roots of $C$. sativa were extracted by rapid immersion in chloroform, silylated, and analyzed by gas chromatography (GC). Molecular components were identified from both their GCretention behaviour and characteristic mass spectra (MS), and quantified by flame ionization detection (FID).

\subsection{Leaf cuticular wax}

Leaf samples were analyzed at two different growth stages along the vegetative or primary stem, identified as "top" (youngest) and "bottom" (oldest) (Fig. 1A). Total leaf wax loads were not significantly different between the top and bottom portions, which accumulated $6.3 \pm 1.1 \mu \mathrm{g} \mathrm{cm}^{-2}$ and $5.8 \pm 0.8 \mu \mathrm{g} \mathrm{cm}^{-2}$ (mean \pm SD., $n=4$; Fig. 2, inset), respectively. However, they differed in their relative compositions of wax esters and alkanes (T-test, two-sided $\mathrm{P}<0.05)$. Wax esters, were the dominant compounds in both top and bottom leaves (64 and $69 \mathrm{~mol} \%$, respectively), followed by very-long-chain

primary fatty alcohols, ranging from $\mathrm{C}_{22}$ to $\mathrm{C}_{34}(26-27 \mathrm{~mol} \%)$, fatty acids (4-5 mol \%) and 
odd carbon number alkanes $\left(\mathrm{C}_{29}-\mathrm{C}_{33}\right)(3$ and $1 \mathrm{~mol} \%$ in top and bottom leaves, respectively) (Fig. 2).

Scanning electron microscopy studies of leaf surfaces revealed an absence of epicuticular wax crystal structures (Fig. 1H). Similarly, smooth surfaces without crystals were observed on leaves of $A$. thaliana ecotypes Wassilewskija (WS), Landsberg erecta (Ler) (Jenks et al., 1995), and C24 (Teusink et al., 2002). Wax loads in these $A$. thaliana ecotypes $\left(1.6,1.0\right.$, and $1.1 \mu \mathrm{g} \mathrm{cm}^{-2}$, respectively) were comparable to total waxes accumulated on $C$. sativa leaves. It is possible that the leaves on these species are covered solely by an amorphous wax layer because a critical amount of lipids is necessary to form crystals, although it is well documented that crystal formation is also influenced by wax chemical composition (Baker, 1982; Rowland et al., 2006). The wax loads on leaves of Brassica oleracea and $B$. napus are much higher $\left(25-50 \mu \mathrm{g} \mathrm{cm}^{-2}\right)$ than C. sativa leaves and their leaf surfaces are characterized by densely packed dendritic tubes of wax crystals (Baker, 1974; Holloway et al., 1977). The leaf wax compositions of B. oleracea and $B$. napus are also very different, being dominated by alkanes, ketones, and secondary alcohols.

\subsubsection{Composition of wax esters found in leaf cuticular wax}

Alkyl esters of long-chain fatty acids and long-chain fatty alcohols (wax esters), with carbon chain-lengths ranging from $\mathrm{C}_{38}$ to $\mathrm{C}_{50}$, were present in the waxes extracted from leaves but not in those extracted from other organs. Wax esters were quantified by GCFID, and equaled $4.7 \pm 0.6 \mu \mathrm{g} \mathrm{cm}^{-2}$ in top leaves and $4.6 \pm 0.5 \mu \mathrm{g} \mathrm{cm}^{-2}$ in bottom leaves (Fig. 2, inset). By comparison, wax ester content in Ler and WS ecotypes of $A$. 
thaliana stem cuticular wax is 0.17 and $0.2 \mu \mathrm{g} \mathrm{cm}^{-2}$, respectively, with only traces present in the rosette leaf cuticular wax fractions $\left(0.002 \mu \mathrm{g} \mathrm{cm}^{-2}\right)$ (Jenks et al., 1995).

Saturated wax ester homologues were identified according to their molecular ions $\left(\mathrm{M}^{+}\right)$. Like wax esters found in cuticular waxes of other species, each $C$. sativa wax ester peak was composed of a mixture of constitutional isomers. To characterize these isomeric mixtures, we compared the relative amounts of the acyl moieties within each ester group present in the mass spectrum. The alcohol $\left(\mathrm{R}^{\prime} \mathrm{OH}\right)$ and acid $(\mathrm{RCOOH})$ moieties of the isomeric mixtures were identified according to their most abundant diagnostic fragments, $\left[\mathrm{R}^{\prime}-\mathrm{H}\right]^{+*}$ and $\left[\mathrm{RCOOH}_{2}\right]^{+}$, respectively, which are products of cleavage near the ester bond (Table 1) (Aasen et al., 1971; Lai et al., 2007; Sümmchen et al., 1995; Urvanova et al., 2012). For each even-numbered wax ester $\left(\mathrm{C}_{38}-\mathrm{C}_{48}\right)$, the protonated acyl fragments $\left[\mathrm{RCOOH}_{2}\right]^{+}$had higher intensities and were used to calculate the abundance of each wax ester isomer $(n=4)$. The most abundant ions representing the alcohol moiety of the esters were radical cations $\left[\mathrm{R}^{\prime}-\mathrm{H}\right]^{+*}$, produced by elimination of the acyl moiety; these were identified to confirm isomer structure.

Table 1 details the relative amounts of different isomers in the major wax ester homologues $\left(\mathrm{C}_{38}, \mathrm{C}_{40}, \mathrm{C}_{42}, \mathrm{C}_{44}, \mathrm{C}_{46}, \mathrm{C}_{48}\right.$ and $\left.\mathrm{C}_{50}\right)$. Small amounts of odd-carbon number ester homologues (0.06-0.16 $\mu \mathrm{g} \mathrm{cm}^{-2}$ each) with carbon chain lengths $\mathrm{C}_{41}, \mathrm{C}_{43}, \mathrm{C}_{45}, \mathrm{C}_{47}$ and $\mathrm{C}_{49}$, were also identified (data not shown); their isomer compositions are not reported here because the method is reliable only when substantial concentrations of components are present in the mixture (Aasen et al., 1971). The most abundant wax esters were $\mathrm{C}_{42}, \mathrm{C}_{44}$ and $\mathrm{C}_{46}$, which comprised 18,26 and $13 \mathrm{~mol} \%$ of the total wax esters of bottom leaves, respectively, and 19,25 and $18 \mathrm{~mol} \%$ of the total wax esters in top leaves, respectively (Fig. 2). Substantial amounts of $\mathrm{C}_{40}(10-11 \mathrm{~mol} \%)$, and $\mathrm{C}_{48}(8-11$ mol \%) were also found in both young and old leaves. The predominant wax ester 
isomers were composed of eicosanoic acid (20:0) and 1-tetracosanol (24:0-OH), constituting $68 \%$ of the isomeric molecular species in the $\mathrm{C}_{44}$ wax esters, eicosanoic acid (20:0) and 1-docosanol (22:0-OH), constituting $52 \%$ of the $\mathrm{C}_{42}$ wax esters, and eicosanoic acid (20:0) and 1-hexacosanol (26:0-OH), constituting $63 \%$ of the $\mathrm{C}_{46}$ wax esters (Table 1).

\subsubsection{Acyl chain compositions in wax esters}

The predominant fatty acids in the wax esters were hexadecanoic acid (16:0) (23 mol $\%$ ), eicosanoic acid (20:0) (46 mol \%), and docosanoic acid (22:0) (18 mol \%) (Fig. 3A). Approximately $6 \mathrm{~mol} \%$ of the wax esters contained the 24:0 acyl moiety. Only a small proportion of wax esters (4 mol \%) contained the 18:0 acyl moiety (Fig. 3A) even though roughly equal amounts of free hexadecanoic (16:0) and octadecanoic (18:0) acids were present in leaf cuticular waxes (Fig. 2 and 3A). This observation may imply that at least two wax synthases are involved, one more specific for 16:0 with little activity for 18:0, and one for $20: 0$ and 22:0 acyl substrates. By contrast, 16:0 is the predominant acyl moiety ( 75\%) of the wax esters found in A. thaliana stems (Lai et al., 2007; Li et al., 2008). Our results also show that there is no obvious relationship between the percentages of free and esterified fatty acid (Fig. 3A). For example, even though 20:0 and 22:0 were the most abundant acyl chains in esters the corresponding free fatty acids were not found in top or bottom leaf waxes.

\subsubsection{Alkyl chain compositions in wax esters}

Free and esterified alcohols were compared to infer possible substrates for wax ester synthesis in C. sativa. Free alcohols were quantified by GC-FID (Fig. 2) and ester-bound 
alkyl moieties were deduced from the MS-calculated acyl percentages and the total wax ester chain lengths (Fig. 3B). The most abundant esterified fatty alcohol, 1-tetracosanol (24:0-OH), constituted about $39 \%$ of the ester-bound fraction, whereas 1 -hexacosanol $(26: 0-\mathrm{OH})$ was the most abundant free alcohol (41 mol \%). The 26:0 and 22:0 homologues were the next abundant alkyl moieties in wax esters, representing 24 and $27 \mathrm{~mol} \%$ of the bound alcohols. Longer chain $(\geq 28: 0-\mathrm{OH})$ fatty alcohols were either present in small amounts in the wax esters compared to the corresponding free species (1-octacosanol - 28:0-OH, 1-triacontanol - 30:0-OH), or only found in the free forms (1dotriacontanol - 32:0-OH, 1-tetratriacontanol - 34:0-OH). These observations suggest a preference of the wax synthase enzyme(s) for $\mathrm{C}_{22}-\mathrm{C}_{26}$ species; however, it is also possible that the longer chain alcohols are not readily available at the sites of wax ester synthesis.

\subsection{Stem cuticular wax}

Stem samples representing four different growth stages along the bolt were analyzed for their wax compositions (Fig. 1A). "Top" and "side" (secondary stem/shoot) samples represented young stem, whereas "middle" and "bottom" constituted intermediate and older primary stem portions, respectively. All these yielded mixtures of very-long-chain aliphatics, dominated by alkanes, and pentacyclic triterpenes with small amounts of primary fatty alcohols and free fatty acids (Fig. 4). Surprisingly, secondary alcohols and ketones, which are abundant components of the cuticular waxes of $A$. thaliana stems (LiBeisson et al, 2013) and B. napus organs (Molina et al., 2008; Pu et al., 2013), were not found in the analyzed C. sativa organs.

Chromatographic analysis of wax components also revealed a major difference in the total wax coverage between the top and bottom of the shoot (Fig. 4, inset). Wax loads 
correlated with the presence and density of crystals. The highest wax amount and crystal density was found in top stems $\left(15.5 \pm 6.5 \mu \mathrm{g} \mathrm{cm}^{-2}\right.$; mean $\left.\pm \mathrm{SD}, n=4\right)$, followed by side shoots $\left(11.0 \pm 5.8 \mu \mathrm{g} \mathrm{cm}^{-2}\right)$. Side shoots presented a smaller number of crystals per area unit than top stems (Fig. 1B-E). In middle and bottom stem samples, the extracted waxes dropped to $5.3 \pm 2.7 \mu \mathrm{g} \mathrm{cm}^{-2}$ and $1.6 \pm 0.9 \mu \mathrm{g} \mathrm{cm}^{-2}$, respectively. The fact that no crystals were observed on these lower surfaces (Fig. 1F-G) suggests that a critical wax concentration for crystallization was not reached. Because the compound class distribution remains similar along the stem (Fig. 4), it is unlikely that the lack of crystals is attributed to differences in chemical composition. Differences in surface microstructure may reflect different eco-physiological roles of cuticular wax in top versus bottom stem. For example, epidermal surface features like wax crystals create a micro-scale surface roughness that is too small for insect claws to grip, effectively reducing the contact area between the plant surface and insect footpads thereby reducing insect traction (Whitney and Federle, 2013). The differential presence of wax crystals on the top portion of the stem versus the bottom portion of the stem could be indicative of mechanisms to deter herbivorous insects from the reproductive organs (flowers) of $C$. sativa.

Pentacyclic triterpenoids of the ursane, oleanane and lupane groups, which constitute widespread plant natural products with nutraceutical properties (Jäger et al., 2009), were abundant constituents of $C$. sativa cuticular stem waxes. Trimethylsilyl (TMSi) ether and/or ester derivatives of erythrodiol, betulin, oleanolic acid, betulinic acid and ursolic acid were identified by direct comparison with mass spectra and chromatographic retention behavior of authentic standards (Fig. S1). Three compounds, namely $\alpha$-amyrin, $\beta$-amyrin and uvaol, were identified by comparison with published spectra (Heinzen et al., 1996; Wang et al., 2011; Wang et al., 2010) (Fig. S2 A, E, F). In rapidly expanding shoots, namely top and side samples, the relative abundances of each of these 
secondary metabolites were comparable. Ursane-type triterpenoids, corresponding to $\alpha$ amyrin and its metabolites ursolic acid and uvaol, were predominant (71\%; Fig. 4). Oleanane-derived triterpenoids, represented by $\beta$-amyrin and two of its oxidized derivatives, oleanolic acid and erythrodiol, constituted $24 \%$ of the total triterpenoid fraction. Betulin and betulinic acid, but not their precursor, lupeol, constituted $5 \%$ of the total cuticular waxes in young stems. In more mature stems (middle stem), the relative content of $\alpha$-amyrin and $\beta$-amyrin decreased but was compensated by a relative increase in the proportions of their metabolites ursolic acid, uvaol, and erythrodiol. Likewise, an increase in the proportion of betulin was also observed in this fraction. Nevertheless, the total content of pentacyclic triterpenoid components, as well as the total wax coverage, decreased substantially in the bottom (older) portions of stems, indicating that increasing stem girth and wax production are not necessarily synchronized processes in C. sativa stems.

\subsection{Flower wax}

Identified wax components found in wax extracts from whole open flowers (Fig. 5) totaled $264 \pm 48 \mu \mathrm{g} / \mathrm{g}$ flower sample, and corresponded to $40 \%$ of the total chromatographic area. Most of the unidentified peaks had spectra characteristic of disaccharides. Alkanes were the most abundant aliphatic wax components $(68 \%$ of the identified wax load) with the most abundant alkane being unbranched nonacosane $\left(\mathrm{C}_{29}\right)$. Branched alkanes, namely iso-nonacosane $\left(\mathrm{C}_{29}\right.$ iso $)$ and iso-hentriacontane $\left(\mathrm{C}_{31}\right.$ iso), were identified from diagnostic ions $[\mathrm{M}-43]^{+}\left(\left[\mathrm{M}-\mathrm{C}_{3} \mathrm{H}_{7}\right]^{+}\right)$and $[\mathrm{M}-15]^{+}\left(\left[\mathrm{M}^{+}-\mathrm{CH}_{3}\right]^{+}\right)$ which were much more abundant than in their respective $n$-alkanes (Bauer, 2002). These iso-alkanes were present in relatively large amounts. Free fatty acids and fatty 
alcohols (i.e. octadecanol) constituted $16 \%$ and $1 \%$ of the flower wax mass, respectively (Fig. 5). The triterpenoid fraction (15\% of the identified aliphatics) included $\alpha$ - and $\beta$ amyrin (Fig. S2), and a mixture of co-eluting sterols, namely campesterol-TMSi ether (diagnostic ions: $\mathrm{m} / \mathrm{z} 129,343,367,382,472[\mathrm{M}]^{+}$), and two unidentified sterols with [M] ${ }^{+}$ $\mathrm{m} / \mathrm{z} 470$ and 481.

\subsection{Seed wax}

Mature $C$. sativa seeds have a size intermediate to the size of $A$. thaliana and $B$. napus seeds (Li et al., 2006) (Fig. S3). If modeled as an ellipsoid, C. sativa seed has a surface area of $0.062 \mathrm{~cm}^{2}$, which is 2 times smaller than that of $B$. napus and 17 times larger than A. thaliana seeds (Li et al., 2006). Although we cannot assume that the extracted waxes are exclusively deposited at the seed surface because both cuticle(s) and suberized cells may be present in more internal seed coat layers (Molina et al., 2008), it is useful to normalize wax mass to unit of seed area for the purpose of comparison with other $C$. sativa organs and also with published data.

Figure 6 shows the composition of waxes readily extracted from mature seeds of $C$. sativa via rapid immersion in chloroform. The identified components $(70 \%$ of the total chromatographic area) gave a total of $242 \pm 56 \mathrm{ng} \mathrm{cm}^{-2}$, which was the lowest wax coverage of the analyzed $C$. sativa surfaces. This load was in the same range as $A$. thaliana seed surface wax content (370 $\left.\mathrm{ng} \mathrm{cm}^{-2}\right)$ (Li-Beisson et al., 2013), and more than $3 \times 10^{3}$ times lower than $B$. napus seed wax coverage, which contains $800 \pm 0.2 \mu \mathrm{g}$ wax $\mathrm{cm}^{-2}$ (Molina et al., 2008). Alkanes, mainly nonacosane $\left(C_{29}\right)$ and hentriacontane $\left(C_{31}\right)$, and very-long-chain primary fatty alcohols ranging from $\mathrm{C}_{24}$ to $\mathrm{C}_{32}$, including oddnumbered carbon chain lengths, were predominant (Fig. 6). Seed waxes of other 
species of Brassicaceae, namely B. napus and A. thaliana (Beisson et al., 2007; Molina et al., 2008), are instead dominated by nonacosane ( $\mathrm{C}_{29}$ alkane) and its 15 -hydroxy and oxo derivatives, resembling the composition of $A$. thaliana leaf waxes (Rashotte et al., 2001). Most of the primary fatty alcohols in $C$. sativa seed waxes were $C_{28}-C_{32}$ in length (including odd-chain homologues), much longer than the predominant fatty alcohols found in the waxes of other organs analyzed. This indicates that further elongation of very-long-chain fatty acyl-CoAs occurs in seeds, perhaps by a seed coat-specific fatty acid elongase. A fatty acyl reductase capable of reducing the $\mathrm{C}_{28}-\mathrm{C}_{32}$ fatty acyl-CoAs to fatty alcohols must also be present in seeds.

\subsection{Root wax}

Eight-week-old roots of $C$. sativa plants contain a well-developed suberized periderm, as indicated by the characteristic autofluorescence of cell wall structures observed by fluorescence microscopy (Fig. 1I). Quick solvent immersion allows extraction of periderm-associated waxes (Espelie et al., 1980; Li et al., 2007). Entire C. sativa roots were dipped in chloroform for 1 min and previous studies have shown that most of the waxes extracted by this process derive from the taproot and are likely associated with the suberized periderm (Kosma et al., 2012).

Gas chromatographic analyses of taproot chloroform extracts revealed the presence of a complex mixture of compounds (Fig. S4). To better identify and quantify $C$. sativa root wax constituents, root wax extracts were subjected to solid-phase extraction (SPE) and then fractionation following a previously described procedure (Gutiérrez et al., 2008) with some modifications (see Experimental). Use of this fractionation technique allowed the isolation and identification of approximately $25 \%$ of root wax compounds representing $276 \pm 58 \mu \mathrm{g}$ per gram of root fresh weight (Fig. 7). Identified root wax 
constituents presented a composition similar to $A$. thaliana root waxes (Li et al., 2007), including a profile dominated by alkyl caffeates (62 mol \% of total identified compounds) and alkyl coumarates (27 mol \% of total identified compounds) with traces of alkyl ferulates. The presence of alkyl caffeates is indicative of an acyltransferase activity orthologous to that described in A. thaliana (Kosma et al., 2012) for the synthesis of alkyl caffeates in $C$. sativa taproots. Previously unreported in $A$. thaliana, $\mathrm{C}_{16}$ alkyl coumarates and caffeates and trace amounts of $\mathrm{C}_{17}$ and $\mathrm{C}_{21}$ alkyl caffeates were found in the root waxes of $C$. sativa. Other identified root wax constituents included the sterols campesterol, ergosterol, and $\beta$-sitosterol $\left(\mathrm{C}_{28: 1}, \mathrm{C}_{29: 2}\right.$, and $\mathrm{C}_{29: 1}$ sterols, respectively), $\mathrm{C}_{18}-\mathrm{C}_{28}$ primary fatty alcohols, and $\mathrm{C}_{20}-\mathrm{C}_{24}$ monoacylglycerols (both $\alpha$ and $\beta$ stereoisomers). Lanosterol, taraxerol, $\beta$-amyrin, glutinol, $\alpha$-amyrin, and cycloartenol peaks represented $4 \%, 6 \%, 2 \%, 6 \%, 3 \%$, and $2 \%$, respectively, of the total chromatogram area of fraction B. An additional non-sterol triterpenoid representing $<1 \%$ of the total chromatogram area of fraction B was tentatively identified as taraxasterol but could not be distinguished from its geometric isomer $\Psi$-taraxasterol based on the mass spectrum (Fig. S2). The presence of a different suite of triterpenoids in root versus stem waxes suggests the presence of triterpene synthases with different specificities in these respective organs.

\section{Conclusions}

This study provides qualitative and quantitative information on the surface waxes of C. sativa aerial and underground organs. Substantial chemical diversity was observed in the wax mixtures extracted from the various organs. Despite the short phylogenetic distance from $A$. thaliana, $C$. sativa presented organ-specific wax compositions that were in most instances substantially different from those of $A$. thaliana. The information 
presented herein will serve as a basis for future genetic and biochemical studies on plant wax and natural product biosynthesis, and to evaluate the impact of such waxes on Camelina sativa's resistance to stresses. For example, our results indicate that the stem cuticle of this species is a non-sterol, triterpene-rich lipid layer, thus representing an attractive system to study the metabolism of such bioactive compounds. Modification of surface wax loads or compositions of $C$. sativa may further improve the protective properties of these hydrophobic barriers and thereby further increase the stress-resistant attributes of this oilseed crop. Further, it will help to establish $C$. sativa as a platform for the production of value-added natural products of industrial utility in addition to its use as an oil seed crop.

\section{Experimental}

\subsection{Plant material and growth conditions}

Camelina sativa (L.) Crantz cv. Celine seeds were obtained from Dr. Chaofu Lu (Montana State University, USA). Surface sterilized seeds were planted on autoclaved PRO-MIX MPV potting mixture (Premier Tech Horticulture) containing 20-20-20 fertilizer and grown in an environmental chamber at $22^{\circ} \mathrm{C}$ in a 16-h-light/8-h-dark photoperiod with $100-120 \mu \mathrm{E} \mathrm{m}^{-2} \mathrm{~s}^{-1}$ light intensity and ambient humidity. Seeds were harvested from fully mature, dry plants by manually opening seed pods and then carefully sieving away any non-seed material.

\subsection{Wax extractions}


The surface waxes of aerial organs were all extracted by immersion of organs in the low polarity solvent chloroform. Leaf, stem, and flower organs from 7-8-week-old plants were dipped for $30 \mathrm{~s}$ in enough chloroform $(8-24 \mathrm{~mL})$ to cover the organ completely. The solution also contained $1 \mu \mathrm{g}$ each of $n$-tetracosane (24:0 alkane), 1-pentadecanol (15:0$\mathrm{OH})$ and heptadecanoic acid (17:0), which served as internal quantification standards. The $n$-tetracosane, 1-pentadecanol and heptadecanoic acid standards were obtained from Sigma-Aldrich and were at least $98 \%$ purity. For the flowers, $15-20$ partially or fully opened flowers were used. The fresh weight of the flowers was measured prior to dipping. For the leaves, two leaves were taken just below the first silicle ('top' leaves) and two leaves were taken about 5-9 cm above the soil ('bottom' leaves). The leaves were scanned to determine the total surface area. For the stems, 7 to $8 \mathrm{~cm}$ sections were taken from different parts of the stem: (1) starting just below the first fully formed secondary inflorescence ('top stem'), (2) centered around the $15^{\text {th }}$ and $16^{\text {th }}$ leaves counting from the bottom ('middle' stem), (3) starting about $5 \mathrm{~cm}$ above the soil ('bottom' stem), and (4) from a mature secondary inflorescence starting immediately next to the point of attachment with the primary inflorescence ('side' shoot) (see Fig. 1A for visual depiction). The diameters and lengths of the stem sections were measured using a digital caliper to determine the surface area. For seed waxes, $100 \mathrm{mg}$ of dry mature seeds were dipped for $2 \mathrm{~min}$ in $8 \mathrm{ml}$ of chloroform containing the internal standards described above. The above chloroform extracts were then evaporated under a gentle stream of nitrogen.

For root wax extractions, the roots from 8-week-old plants were dug out of soil, washed with tap water, air dried at room temperature, and then dipped for $1 \mathrm{~min}$ in chloroform. The solution also contained $5 \mu \mathrm{g}$ each of $n$-tetracosane (24:0 alkane), 1 pentadecanol (15:0-OH), heptadecanoic acid (17:0), tridecyl (13:0)-ferulate, heptadecyl (17:0)-coumarate, and nonadecyl (19:0)-caffeate, which served as internal quantification 
standards. The synthesis and purification of tridecyl (13:0)-ferulate and heptadecyl (17:0)-coumarate is described in Kosma et al., 2012; these standards were $>95 \%$ pure. The synthesis and purification of nonadecyl (19:0)-caffeate is described below; this standard was $>95 \%$ pure. The extracts were filtered through glass wool and then evaporated under a gentle stream of nitrogen gas. The extracts were then subjected to fractionation by solid-phase extraction (SPE) using aminopropyl-phase cartridges (SepPak $^{\text {TM }}$ Vac 3cc, $500 \mathrm{mg}$, Waters Ltd.). The fractionation procedure was similar to that described by (Gutiérrez et al., 2008) with some modifications. The above dried chloroform extracts were redissolved in $0.5 \mathrm{~mL}$ of hexane:chloroform (4:1) and loaded onto separate SPE cartridges, which had been conditioned with $4 \mathrm{~mL}$ of hexane. The columns were then eluted with a sequential series of solvents of increasing polarity: 8 $\mathrm{mL}$ of hexane (fraction $\mathrm{A}$ ), $6 \mathrm{~mL}$ of hexane: chloroform (5:1) (fraction $\mathrm{B}$ ), $8 \mathrm{~mL}$ of dichloromethane (fraction $\mathrm{C}$ ), $8 \mathrm{~mL}$ of chloroform (fraction $\mathrm{D}$ ), $10 \mathrm{~mL}$ of diethyl ether: acetic acid (98:2) (fraction E), and $6 \mathrm{~mL}$ of methanol (fraction F). Fraction A contained alkanes, fraction B contained triterpenoids, fraction $\mathrm{C}$ contained fatty alcohols, alkyl ferulates, sterols, and a series of unidentified compounds; fraction D contained a series of unidentified compounds, fraction E contained alkyl coumarates, alkyl caffeates, and monoacylglycerols. Root wax fractions were evaporated under a gentle stream of nitrogen and analyzed as silylated derivatives by GC-MS as described below (per temperature program used for all waxes except leaf waxes). Root wax constituents from each fraction were quantified using uncorrected peak areas from total ion chromatograms (TIC), unless otherwise noted, relative to internal standards that coeluted with each fraction. Sterols and fatty alcohols were quantified relative to the 1pentadecanol $(15: 0-\mathrm{OH})$ internal standard found in fraction C. Alkyl coumarates and monoacylglycerols were quantified relative to the heptadecyl coumarate (17:0coumarate) internal standard found in fraction E. Alkyl caffeates were quantified relative 
to the nonadecyl caffeate (19:0-caffeate) internal standard found in fraction E. Alkyl ferulates were quantified relative to the tridecyl ferulate (13:0-ferulate) internal standard found in fraction C. Several constituents were quantified using single ions diagnostic of a given class of constituents: the peak areas of the $m / z=249$ fragments were used for the alkyl ferulates relative to the tridecyl ferulate internal standard ion fragment and the peak areas of the $m / z=219$ fragments were used for the 16:0-, 17:0-, and 21:0-caffeates relative to the 19:0-caffeate internal standard ion fragment.

\subsection{GC-FID and GC-MS analysis}

Wax extracts were derivatized by dissolving the samples in $100 \mu \mathrm{L}$ of $N, O-b i s-$ (trimethylsilyl)-trifluoroacetamide (BSTFA) plus $100 \mu \mathrm{L}$ of pyridine. The samples were sealed under nitrogen gas, briefly vortexed, and then incubated for $10 \mathrm{~min}$ at $110{ }^{\circ} \mathrm{C}$. The derivatized samples were allowed to cool down to room temperature and then evaporated under a gentle stream of nitrogen gas. The samples were re-suspended in heptane:toluene $(1: 1 \mathrm{v} / \mathrm{v})$ for analysis by gas chromatography. For chemical identifications, the samples were analyzed on an Agilent 6850 gas chromatograph equipped with an Agilent 5975 mass spectrometer. Splitless injection was used with a HP5-MS column (30 m length, $0.25 \mathrm{~mm}$ inner diameter, $0.25 \mu \mathrm{m}$ film thickness). Temperature settings were as follows: inlet $350^{\circ} \mathrm{C}$, detector $320^{\circ} \mathrm{C}$, oven temperature program was set to $130^{\circ} \mathrm{C}$ for $2 \mathrm{~min}$ and increased to $325^{\circ} \mathrm{C}$ at a rate of $5^{\circ} \mathrm{C}$ per minute, oven temperature was then held at $325^{\circ} \mathrm{C}$ for $10 \mathrm{~min}$. The helium flow rate was set at $1.5 \mathrm{~mL}$ per minute. For most quantifications, the samples were analyzed on an Agilent 6890 gas chromatograph equipped with a flame ionization detector (FID). Splitless injection was used with a HP5-MS column (30 m length, $0.25 \mathrm{~mm}$ inner diameter, $0.25 \mu \mathrm{m}$ film thickness). Temperature settings were as follows: inlet $350^{\circ} \mathrm{C}$, 
detector $320^{\circ} \mathrm{C}$, oven temperature program was set to $130^{\circ} \mathrm{C}$ for 2 min and increased to $325^{\circ} \mathrm{C}$ at a rate of $5^{\circ} \mathrm{C}$ per minute, oven temperature was then held at $325^{\circ} \mathrm{C}$ for 10 min. The helium flow rate was set at $1.5 \mathrm{~mL}$ per minute. For leaf waxes, which contained very-long-chain wax esters, temperature settings were as follows: inlet $350^{\circ} \mathrm{C}$, detector $345^{\circ} \mathrm{C}$, oven temperature program was set to $130^{\circ} \mathrm{C}$ for 2 min and increased to $345^{\circ} \mathrm{C}$ at a rate of $5^{\circ} \mathrm{C}$ per minute, oven temperature then stayed at $345^{\circ} \mathrm{C}$ for $10 \mathrm{~min}$. The helium flow rate was set at $1.5 \mathrm{~mL}$ per minute. Compounds were identified by their relative retention times and characteristic mass spectra by comparison to authentic standards (Fig. S1), or to published MS data (Bauer, 2002; Christie, 2013; Heinzen et al., 1996; Wang et al., 2011; Wang et al., 2010).

\subsection{Determination of wax ester calibration response factors}

Because split / splitless injection is known to bias against high molecular weight compounds, calibration curves for wax esters (WEs) with overall carbons $\mathrm{C}_{38}, \mathrm{C}_{40}, \mathrm{C}_{42}$, $\mathrm{C}_{44}$ and $\mathrm{C}_{46}$ were generated using commercially available standards (Nu-Check Prep Inc., Elysian, MN). Standard curves were generated as follows (modified from Iven et al., 2013): 1) three independent replicate mixtures of WE standards were prepared and used to generate a dilution series of analytes containing $0.002-0.160 \mathrm{mg}$ of each WE and analyzed by GC-FID under the same experimental conditions as the $C$. sativa wax samples; 2) each individual dilution was spiked with a constant amount (1 $\mu \mathrm{g})$ of internal standard ( $n$-tetracosane), which was the same amount of IS used for the analysis of $C$. sativa waxes; 3) calculation of normalized peak areas (peak area/standard area) versus WE amount (mg) generated non-linear (third order polynomial) regression curves $\left(\mathrm{R}^{2}\right.$ $>0.98$ ) in the range of the standard amounts (Fig. S5 A-E). These calibration curves

were generated using Prism 6 software package (GraphPad Software, Inc., La Jolla, CA, 
USA). Significant differences in detector response were found with increasing analyte molecular weight. As a result, each wax ester amount was interpolated from their respective calibration curves, with the exception of $\mathrm{C}_{48}$ and $\mathrm{C}_{50}$ for which the $\mathrm{C}_{46}$ calibration curve was used to estimate their loads in samples. Calibration curve coefficients are shown in Fig. S5 F.

\subsection{Calculation of seed wax surface area}

A. thaliana and B. napus seeds have been modelled as ellipsoids and spheres, respectively, to calculate surface areas (Li et al., 2006). C. sativa seeds have a shape similar to that of $A$. thaliana seeds and thus were modeled as ellipsoids. We examined 30 seeds using a stereomicroscope (Leica M205C) and calculated seed dimensions (i.e. long and short axis lengths) using Leica LAS EZ software, which allows measuring and annotation (see example in Supplemental Figure 3). Averages of such dimensions were used to calculate the ellipsoid surface area with an online calculator (http://keisan.casio.com/exec/system/1223392149).

\subsection{Nonadecyl caffeate synthesis and purification}

Nonadecyl caffeate (19:0-caffeate) was synthesized via modification of methods described by Spener and Mangold, 1972. Potassium salts of caffeic acid were first prepared by reacting equimolar amounts of caffeic acid (Sigma-Aldrich) with potassium hydroxide in an alcoholic solution (ethanol) at room temperature. Ethanol was removed by evaporation under nitrogen gas at $50^{\circ} \mathrm{C}$ leaving a dry residue of potassium caffeate. Equimolar amounts of potassium caffeate and commercially available nonadecyl methanesulfonate (Nu-Chek Prep, Inc.) were mixed in $\mathrm{N}, \mathrm{N}$-dimethylformamide under 
nitrogen gas with constant stirring at $120^{\circ} \mathrm{C}$ for $4 \mathrm{~h}$ in a silicon oil bath. The reaction mixture was allowed to cool to room temperature and washed with 1 volume of water three times. The organic phase of the washed reaction product was chromatographed on silica thin-layer chromatography plates (PK6F; Whatman) using multiple developments with $3 \%$ ethanol in chloroform. The nonadecyl caffeate band was identified by fluorescence quenching under UV light. Nonadecyl caffeate was eluted from the silica with chloroform:methanol:water $(5: 5: 1, \mathrm{v} / \mathrm{v} / \mathrm{v})$ and recovered in the chloroform phase after phase partitioning by addition of chloroform and $0.88 \% \mathrm{KCl}(\mathrm{w} / \mathrm{v})$, followed by washing the chloroform phase twice with methanol:water $(1: 1, v / v)$ and drying of the organic phase over sodium sulfate. Extracts were evaporated to dryness under nitrogen gas, recovered as waxy solids, desiccated for $2 \mathrm{~d}$, and dry weights collected. Purity was $>95 \%$ as determined by GC-MS of the silylated product and TLC analysis of the underivatized products.

\subsection{Microscopy}

\subsubsection{Scanning electron microscopy}

Stems from 7-8-week-old C. sativa plants were air dried on stubs and coated with gold-palladium particles using a Hummer VII sputter coater (Anatech Ltd.). Leaves from these plants were placed directly onto a pre-cooled cryo stage for imaging. The samples were examined in a VegallXMU variable pressure scanning electron microscope (Tescan) at an accelerating voltage of $15 \mathrm{kV}$.

\subsubsection{Fluorescence microscopy}


The roots from 8-week-old plants were dug out of the soil and carefully brushed clean. Thin sections were made by hand using a razor blade. The sections were mounted in $50 \%$ glycerol and observed under UV light using a using an Axio Imager M2 compound fluorescent microscope (Zeiss).

\section{Acknowledgments}

We thank Micaëla Chacón and Tanya Hiebert (Dept. of Biology, Carleton University) for assistance with the lipid extractions, Dr. Jianqun Wang (Carleton University Nano Imaging Facility) for assistance with the SEM imaging, and Debora França (Algoma University, funded by the Brazilian Science Without Borders Program) for preparing publication-quality mas spectral figures. We thank Prof. John Ohlrogge (Michigan State

University) for use of gas chromatographs and general support. This work was funded by grants from the Natural Sciences and Engineering Research Council of Canada (O.R. and I. M.), Algoma University (I.M.), and the National Science Foundation of the United States (grant no. MCB-0615563) and the Great Lakes Bioenergy Research Center (under Department of Energy contract no. DE-AC02-05CH11231) (D.K.K.).

\section{Figure Legends}

Fig. 1. Images of Camelina sativa organs analyzed for surface wax composition.

(A) Eight-week-old plant highlighting stem and leaf regions analyzed. Scale bar $=5 \mathrm{~cm}$.

(B) Scanning electron microscopy (SEM) image of top stem epidermis. Scale bar $=20$

$\mu \mathrm{m}$. (C) SEM close-up image of top stem epidermis. Scale bar $=5 \mu \mathrm{m}$. (D) SEM image of side shoot epidermis. Scale bar $=20 \mu \mathrm{m}$. (E) SEM close-up image of side shoot 
epidermis. Scale bar $=5 \mu \mathrm{m}$. (F) SEM image of middle shoot epidermis. Scale bar $=20$ $\mu \mathrm{m}$. (G) SEM image of bottom shoot epidermis. Scale bar $=20 \mu \mathrm{m}$. (H) SEM image of adaxial surface of leaf taken from middle of the shoot. Scale bar $=20 \mu \mathrm{m}$. (I) Ultraviolet light-excited autofluorescence of tap root cross-section; arrow shows suberized periderm. Scale bar $=200 \mu \mathrm{m}$.

Fig. 2. Cuticular wax components extracted from Camelina sativa leaves by rapid chloroform-dipping. Wax composition from leaves harvested along two positions of the shoot are shown: "top" (younger) and "bottom" (older). * Amounts of C48 and C50 wax esters were calculated using the calibration curve for the C46 standard, therefore the values for these two esters may be less accurate. Inset: total leaf wax coverage; bottom leaf fraction includes odd-chain wax esters, which are not shown in the detailed graph. Mean and standard deviation bars are shown $(n=4)$. Unidentified components represented $4.5 \pm 2.7 \%$ of the total peak area in the chromatogram.

Fig. 3. Chain-length distributions of free and esterified fatty acids (A) and fatty alcohols (B) in Camelina sativa leaf cuticular waxes. Error bars represent standard deviation of the mean $(n=4)$.

Fig. 4. Developmental variation in Camelina sativa stem cuticular wax load and composition. Waxes were isolated from four different sections of the stems ("top" and "side" samples, representing the youngest tissues), intermediate development stage ("mid"), and older stems ("bottom"). Inset: total stem wax coverage by wax class composition. Mean and standard deviation bars are shown $(n=4)$. Note: calibrations curves for triterpenoids were not generated and it is possible that amounts are underestimated here. 
Fig. 5. Profiling of Camelina sativa flower waxes. Mean and standard deviation bars are shown $(n=4) . \mathrm{FW}=$ fresh weight. *The sterol fraction was comprised of a mixture of co-eluting sterols, one of which was identified as the campesterol TMSi-ether.

Fig. 6. Profiling of Camelina sativa seed waxes. Mean and standard deviation bars are shown $(n=4)$.

Fig. 7. Characterization of Camelina sativa root waxes. Chain length distribution of individual wax components identified in root extracts per gram of fresh weight (FW). Mean and standard deviation bars are shown $(n=4)$. MAGs: monoacylglycerols (C20C24 refer to the chain lengths of the acyl moieties esterified to glycerol). Coumarates, ferulates and caffeates represent alkyl esters of each hydroxycinnamic acid derivative (C16-C22 represent the chain lengths of the alcohol part of these esters). $\mathrm{FW}=$ fresh weight.

\section{Table Legends}

Table 1. Relative isomeric composition of saturated wax esters in Camelina sativa leaf cuticular wax and mass spectral data. Values were calculated from the intensities of characteristic ions containing the acyl chain in mass spectra of saturated wax esters. Mean values $(n=4)$ and SD are given for each alkyl ester. 


\section{References}

Aasen, A. J., Hofstetter, H. H., lyengar, B. T., Holman, R. T., 1971. Identification and analysis of wax esters by mass spectrometry. Lipids $6,502-507$.

Baker, E. A., 1974. The influence of environment on leaf wax development in Brassica oleracea var. gemmifera. New Phytol. 73, 955-966.

Baker, E.A., 1982. Chemistry and morphology of plant epicuticular waxes, in: Cutler, D.J., Alvin, K.L., Price, C.E. (Eds) The plant cuticle, Academic Press, London, 139-166. Bauer, S., 2002. The composition of surface waxes of tomato, pepper and eggplant. Ph.D. Dissertation, University of Muenster, Germany. Beisson, F., Li, Y. H., Bonaventure, G., Pollard, M., Ohlrogge, J. B., 2007. The acyltransferase GPAT5 is required for the synthesis of suberin in seed coat and root of Arabidopsis. Plant Cell 19, 351-368.

Bouby, L., 1998. Two early finds of gold-of-pleasure (Camelina sp.) in middle Neolithic and Chalcolithic sites in western France. Antiquity 72, 391-398.

Christie, W. W., 2013. The AOCS Lipid Library. Harwood, J. L. and Weselake, R. J. (Eds). Available at http://lipidlibrary.aocs.org.html.

Colombini, S., Broderick, G. A., Galasso, I., Martinelli, T., Rapetti, L., Russo, R., Reggiani, R., 2014. Evaluation of Camelina sativa (L.) Crantz meal as an alternative protein source in ruminant rations. J. Sci. Food Agric. 94, 736-743.

Espelie, K. E., Sadek, N. Z., Kolattukudy, P. E., 1980. Composition of suberin-associated waxes from the subterranean storage organs of seven plants, parsnip, carrot, rutabaga, turnip, red beet, sweet potato and potato. Planta 148, 468-476.

Francis, A., Warwick, S., 2009. The biology of Canadian weeds. 142. Camelina alyssum (Mill.) Thell.; C. microcarpa Andrz. ex DC.; C. sativa (L.) Crantz. Can. J. Plant Sci. 89, 791-810. 
Franke, R., Schreiber, L., 2007. Suberin - a biopolyester forming apoplastic plant interfaces. Curr. Opin. Plant Biol. 10, 252-259.

Gutiérrez, A., Rodríguez, I. M., Del Rio, J. C., 2008. Chemical composition of lipophilic extractives from sisal (Agave sisalana) fibers. Ind. Crop. Prod. 28, 81-87.

Heinzen, H., de Vries, J. X., Moyna, P., Remberg, G., Martinez, R., Tietze, L. F., 1996. Mass Spectrometry of Labelled Triterpenoids: Thermospray and Electron Impact Ionization Analysis. Phytochem. Analysis 7, 237-244.

Holloway, P. J., Brown, G. A., Baker, E. A., Macey, M. J. K., 1977. Chemical composition and ultrastructure of the epicuticular wax in three lines of Brassica napus (L). Chemistry and Physics of Lipids 19, 114-127.

Iskandarov, U., Kim, J., Cahoon, E., 2014. Camelina: an emerging oilseed platform for advanced biofuels and bio-based materials. In: McMann, M., Buckeridge, M., Carpita, N. (Eds.), Plants and BioEnergy, Advances in Plant Biology 4. Springer, New York, pp. 131140.

Iven, T., Herrfurth, C., Hornung, E., Heilmann, M., Hofvander, P., Stymne, S., Zhu, L. H., Feussner, I., 2013. Wax ester profiling of seed oil by nano-electrospray ionization tandem mass spectrometry. Plant Methods 9, 24.

Jäger, S., Trojan, H., Kopp, T., Laszczyk, M. N., Scheffler, A., 2009. Pentacyclic triterpene distribution in various plants -rich sources for a new group of multi-potent plant extracts. Molecules 14, 2016-2031.

Jenks, M., Tuttle, H. A., Eigenbrode, S. D., Feldmann, K. A., 1995. Leaf epicuticular waxes of the eceriferum mutants in Arabidopsis. Plant Physiol. 108, 369-377.

Jetter, R., Kunst, L., Samuels, A.L., 2006. Composition of plant cuticular waxes, in: Riederer, M., Müller, C. (Eds) Biology of the plant cuticle, Annual Plant Reviews, Volume 23, Blackwell Publishing, 145-181. 
Kerstiens, G., 1996. Signalling across the divide: a wider perspective of cuticular structure-function relationships. Trends Plant Sci. 1, 125-129.

Kosma, D. K., Molina, I., Ohlrogge, J. B., Pollard, M., 2012. Identification of an Arabidopsis fatty alcohol:caffeoyl-Coenzyme A acyltransferase required for the synthesis of alkyl hydroxycinnamates in root waxes. Plant Physiol. 160, 237-248.

Lai, C., Kunst, L., Jetter, R., 2007. Composition of alkyl esters in the cuticular wax on inflorescence stems of Arabidopsis thaliana cer mutants. Plant J. 50, 189-196.

Li, F., Wu, X., Lam, P., Bird, D., Zheng, H., Samuels, L., Jetter, R., Kunst, L., 2008. Identification of the wax ester synthase/acyl-coenzyme A: diacylglycerol acyltransferase WSD1 required for stem wax ester biosynthesis in Arabidopsis. Plant Physiol. 148, 97107.

Li, Y., Beisson, F., Ohlrogge, J., Pollard, M., 2007. Monoacylglycerols are components of root waxes and can be produced in the aerial cuticle by ectopic expression of a suberinassociated acyltransferase. Plant Physiol. 144, 1267-1277.

Li, Y., Beisson, F., Pollard, M., Ohlrogge, J., 2006. Oil content of Arabidopsis seeds: the influence of seed anatomy, light and plant-to-plant variation. Phytochemistry 67, 904915.

Li-Beisson, Y., Shorrosh, B., Beisson, F., Andersson, M. X., Arondel, V., Bates, P. D., Baud, S., Bird, D., Debono, A., Durrett, T. P., Franke, R. B., Graham, I. A., Katayama, K., Kelly, A. A., Larson, T., Markham, J. E., Miquel, M., Molina, I., Nishida, I., Rowland, O., Samuels, L., Schmid, K. M., Wada, H., Welti, R., Xu, C., Zallot, R., Ohlrogge, J., 2013. Acyl-lipid metabolism. Arabidopsis Book 11, e0161, doi: 10.1199/tab.0161. Liang, C., Liu, X., Yiu, S. M., Lim, B. L., 2013. De novo assembly and characterization of Camelina sativa transcriptome by paired-end sequencing. BMC Genomics 14, 146. 
Lu, C., Kang, J., 2008. Generation of transgenic plants of a potential oilseed crop Camelina sativa by Agrobacterium-mediated transformation. Plant Cell. Rep. 27, 273278.

Molina, I., Ohlrogge, J. B., Pollard, M., 2008. Deposition and localization of lipid polyester in developing seeds of Brassica napus and Arabidopsis thaliana. Plant J. 53, 437-449.

Mudalkar, S., Golla, R., Ghatty, S., Reddy, A. R., 2014. De novo transcriptome analysis of an imminent biofuel crop, Camelina sativa L. using Illumina GAllX sequencing platform and identification of SSR markers. Plant Mol. Biol. 84, 159-171. Nguyen, H. T., Silva, J. E., Podicheti, R., Macrander, J., Yang, W., Nazarenus, T. J., Nam, J. W., Jaworski, J. G., Lu, C., Scheffler, B. E., Mockaitis, K., Cahoon, E. B., 2013. Camelina seed transcriptome: a tool for meal and oil improvement and translational research. Plant Biotechnol. J. 11, 759-769.

Pu, Y., Gao, J., Guo, Y., Liu, T., Zhu, L., Xu, P., Yi, B., Wen, J., Tu, J., Ma, C., Fu, T., Zou, J., and Shen, J. , 2013. A novel dominant glossy mutation causes suppression of wax biosynthesis pathway and deficiency of cuticular wax in Brassica napus. BMC Plant Biol. 13, 215.

Putnam, D., Budin, J., Field, L., Breene, W., 1993. Camelina: a promising low-input oilseed. In: Janick, J., Simon, J. (Eds.), New Crops. Wiley, New York, pp. 314-322. Rashotte, A. M., Jenks, M. A., Feldmann, K. A., 2001. Cuticular waxes on eceriferum mutants of Arabidopsis thaliana. Phytochemistry 57, 115-123.

Riederer, M., Schreiber, L., 2001. Protecting against water loss: analysis of the barrier properties of plant cuticles. J. Exp. Bot. 52, 2023-2032.

Rowland, O., Zheng, H., Hepworth, S. R., Lam, P., Jetter, R., Kunst, L., 2006. CER4 encodes an alcohol-forming fatty acyl-coenzyme A reductase involved in cuticular wax production in Arabidopsis. Plant Physiol. 142, 866-877. 
Samuels, L., Kunst, L., Jetter, R., 2008. Sealing plant surfaces: cuticular wax formation by epidermal cells. Annu. Rev. Plant Biol. 59, 683-707.

Spener, F., Mangold, H. K., 1972. Reactions of aliphatic methanesulfonates VI. The formation of long-chain esters. Chem. Phys. Lipids. 8, 180-183.

Sümmchen, P., Markstädter, C. and Wienhaus, O.,1995. Esters of Picea abies needle cuticular wax. Phytochemistry 40, 599-600.

Teusink, R. S., Rahman, M., Bressan, R. A., Jenks, M. A., 2002. Cuticular waxes on Arabidopsis thaliana close relatives Thellungiella halophila and Thellungiella parvula. Int. J. Plant Sci. 163, 309-315.

Urbanova, K., Vrkoslav, V., Valterova, I., Hakova, M., Cvacka, J., 2012. Structural characterization of wax esters by electron ionization mass spectrometry. J. Lipid Res. 53, 204-213.

Vogg, G., Fischer, S., Leide, J., Emmanuel, E., Jetter, R., Levy, A.A., Riederer, M., 2004. Tomato fruit cuticular waxes and their effects on transpiration barrier properties: functional characterization of a mutant deficient in a very-long-chain fatty acid $\beta$ ketoacyl-CoA synthase. J. Exp. Bot. 55, 1401-1410. von Wettstein-Knowles, P., 2012. Plant Waxes. eLS. John Wiley and Sons Chichester. Wang, Z., Guhling, O., Yao, R., Li, F., Yeats, T. H., Rose, J. K., Jetter, R., 2011. Two oxidosqualene cyclases responsible for biosynthesis of tomato fruit cuticular triterpenoids. Plant Physiol. 155, 540-552.

Wang, Z., Yeats, T., Han, H., Jetter, R., 2010. Cloning and characterization of oxidosqualene cyclases from Kalanchoe daigremontiana enzymes catalyzing up to 10 rearrangement steps yielding friedelin and other triterpenoids. J. Biol. Chem. 285, 29703-29712. 
Whitney, H., Federle, W., 2013. Biomechanics of plant-insect interactions. Curr. Opin.

Plant Biol. 16, 105-111. 

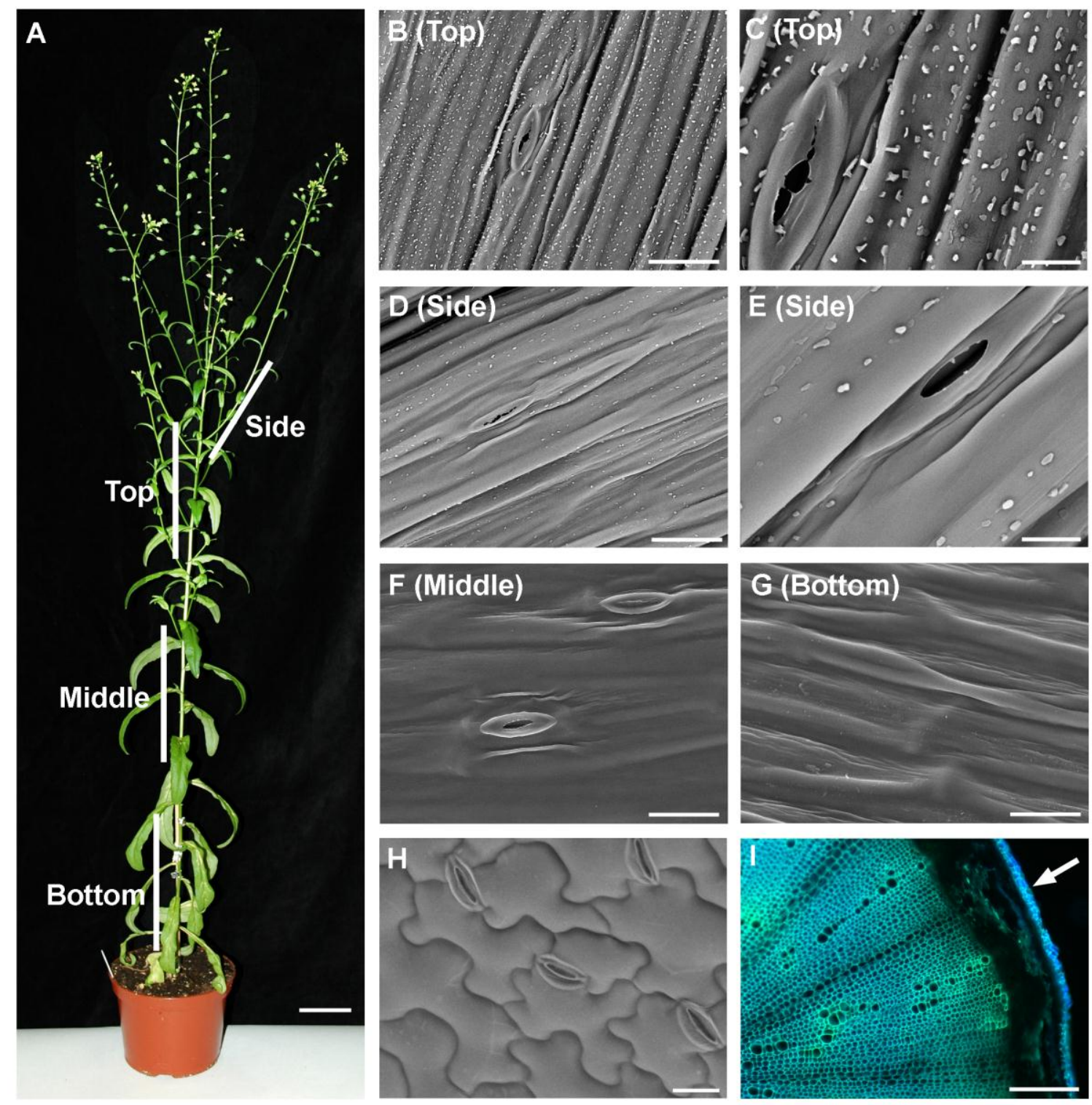


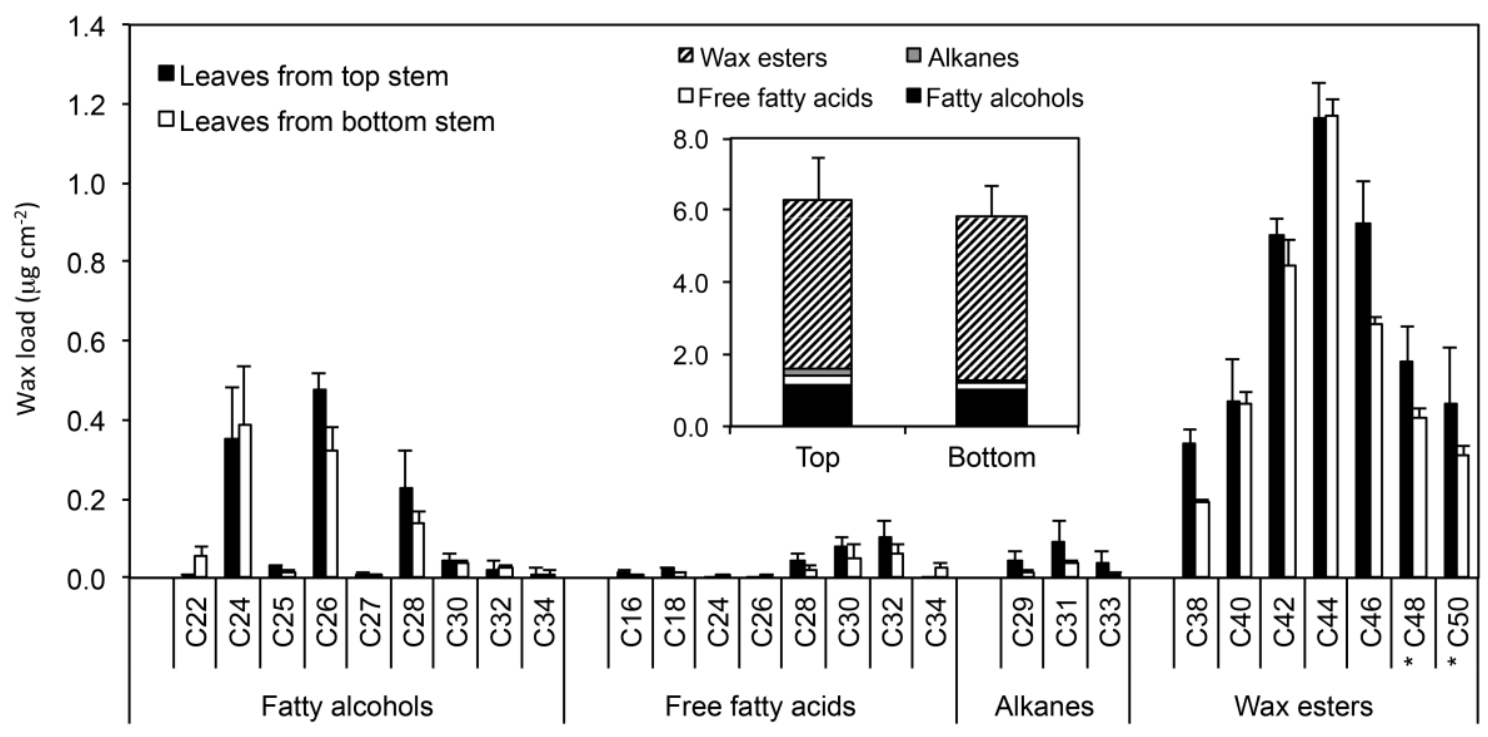



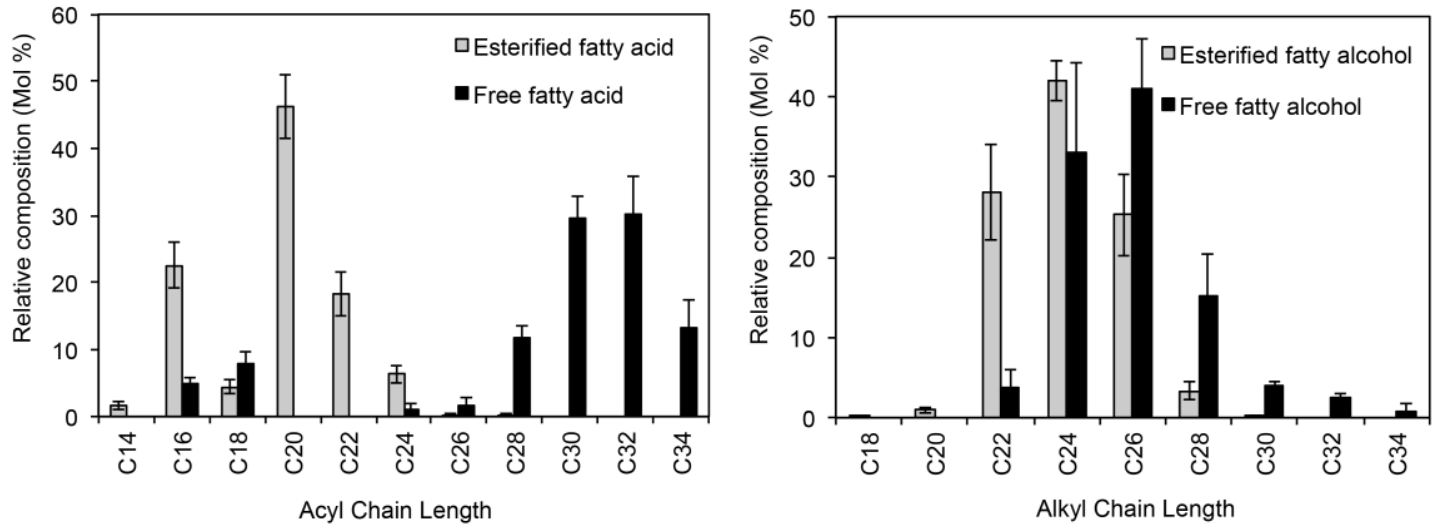


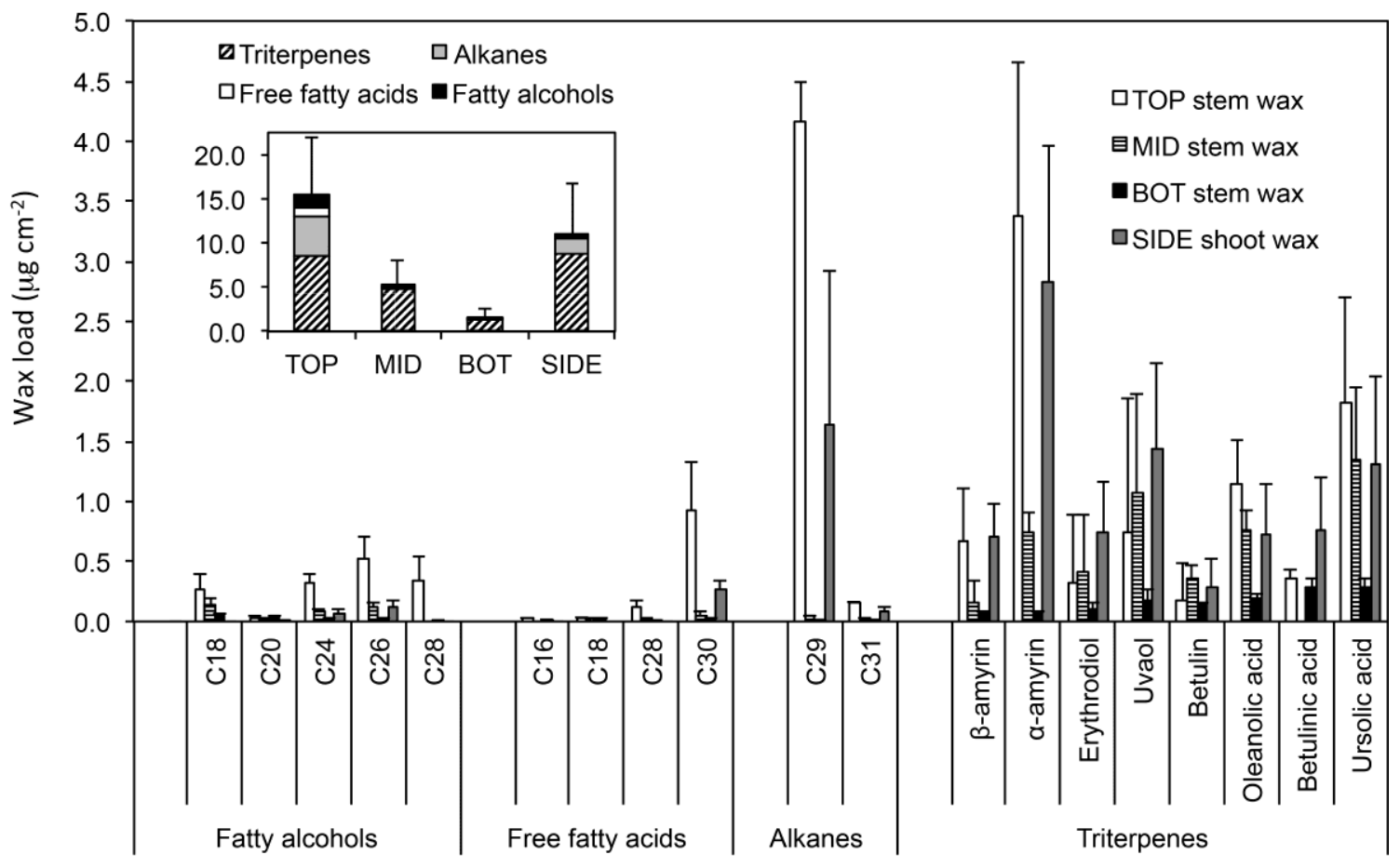




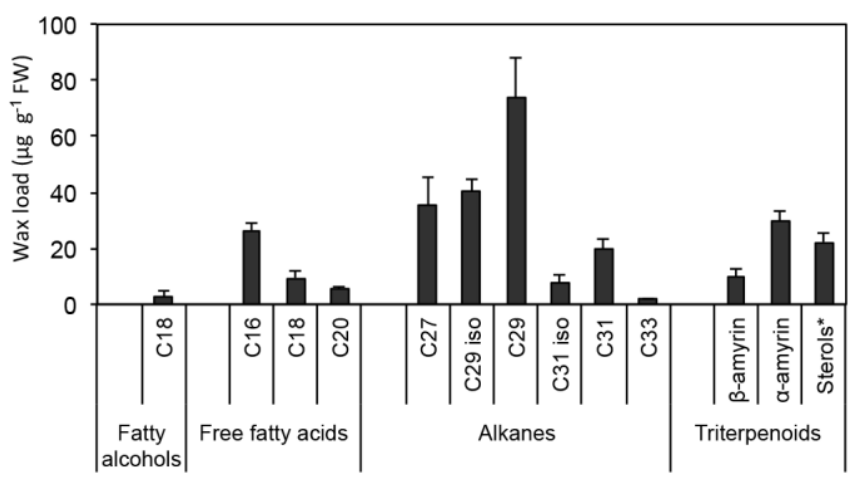




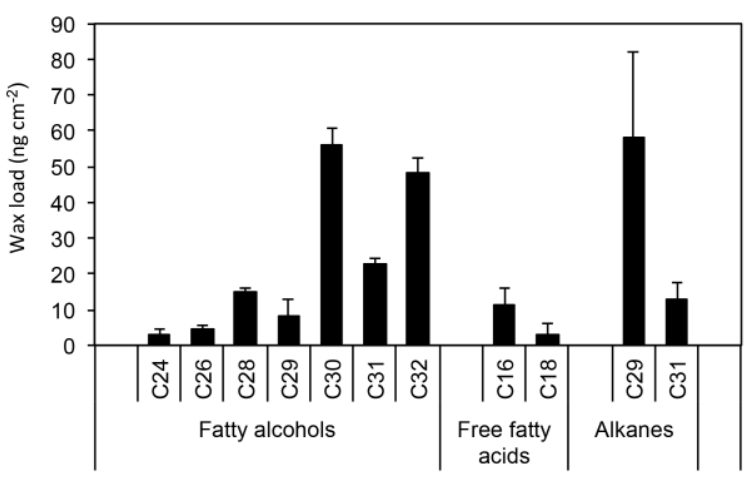




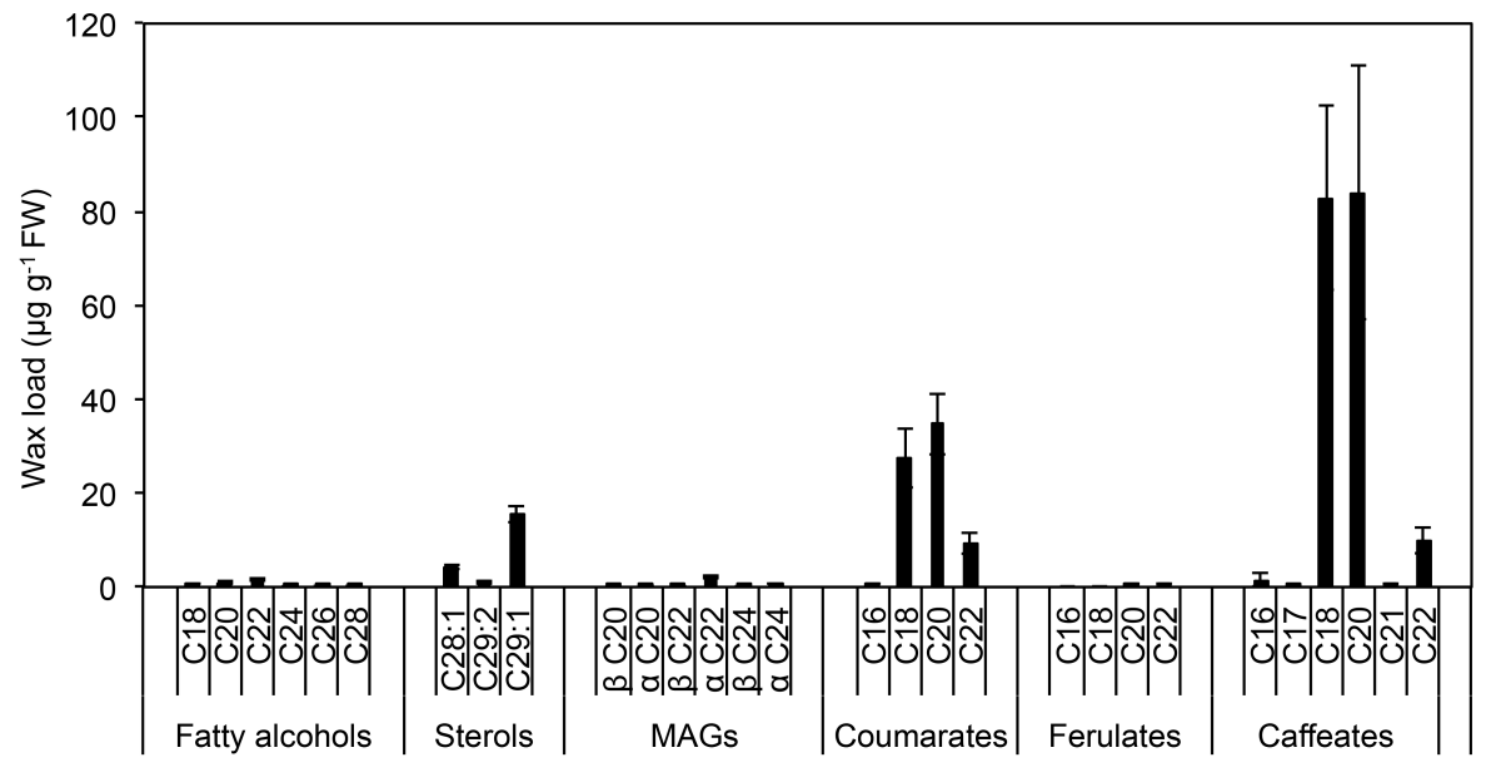


Table 1. Relative isomeric composition of saturated esters in Camelina sativa leaf cuticular wax and mass spectral data. Values were calculated from the intensities of characteristic ions containing the acyl chain in mass spectra of saturated wax esters. Mean values $(n=4)$ and SD are given for each alkyl ester.

\begin{tabular}{|c|c|c|c|c|c|c|}
\hline $\begin{array}{l}\text { Wax ester (WE) } \\
\qquad(\mathrm{CN}: \mathrm{DB})^{\mathrm{a}}\end{array}$ & $\begin{array}{l}\text { Components } \\
\text { (acid-alcohol) }\end{array}$ & $\begin{array}{c}\% \text { of } \\
\text { isomer }^{b}\end{array}$ & SD & {$[\mathrm{M}]^{+}$} & {$[\mathrm{RCO} 2 \mathrm{H} 2]^{+}$} & {$\left[\mathbf{R}^{\prime}-1\right]^{+}$} \\
\hline \multirow[t]{5}{*}{ WE 38:0 } & $14: 0-24: 0$ & 16.44 & 3.78 & 565 & 229 & 336 \\
\hline & 16:0-22:0 & 79.79 & 3.21 & & 257 & 308 \\
\hline & 18:0-20:0 & 1.8 & 0.9 & & 285 & 280 \\
\hline & $20: 0-18: 0$ & 1.2 & 0.7 & & 313 & 252 \\
\hline & Minor isomers ${ }^{c}$ & 0.8 & 0.1 & & & \\
\hline \multirow[t]{5}{*}{ WE 40:0 } & 14:0-26:0 & 4.5 & 2.8 & 593 & 229 & 364 \\
\hline & $16: 0-24: 0$ & 78.4 & 1.5 & & 257 & 336 \\
\hline & 18:0-22:0 & 11.5 & 3.0 & & 285 & 308 \\
\hline & 20:0-20:0 & 3.5 & 1.2 & & 313 & 280 \\
\hline & Minor isomers ${ }^{c}$ & 2.1 & 0.7 & & & \\
\hline \multirow[t]{5}{*}{ WE 42:0 } & $16: 0-26: 0$ & 36.6 & 11.5 & 621 & 257 & 364 \\
\hline & $18: 0-24: 0$ & 8.3 & 1.6 & & 285 & 336 \\
\hline & $20: 0-22: 0$ & 51.9 & 12.1 & & 313 & 308 \\
\hline & $22: 0-20: 0$ & 1.1 & 0.5 & & 341 & 280 \\
\hline & Minor isomers ${ }^{c}$ & 2.1 & 0.8 & & & \\
\hline \multirow[t]{5}{*}{ WE 44:0 } & 16:0-28:0 & 3.4 & 2.5 & 649 & 257 & 392 \\
\hline & $18: 0-26: 0$ & 3.9 & 1.0 & & 285 & 364 \\
\hline & $20: 0-24: 0$ & 68.2 & 2.2 & & 313 & 336 \\
\hline & $22: 0-22: 0$ & 21.9 & 5.5 & & 341 & 308 \\
\hline & Minor isomers ${ }^{c}$ & 2.6 & 0.5 & & & \\
\hline \multirow[t]{2}{*}{ WE 46:0 } & $16: 0-30: 0$ & 1.1 & 0.4 & 677 & 257 & 420 \\
\hline & $18: 0-28: 0$ & 1.1 & 0.3 & & 285 & 392 \\
\hline
\end{tabular}




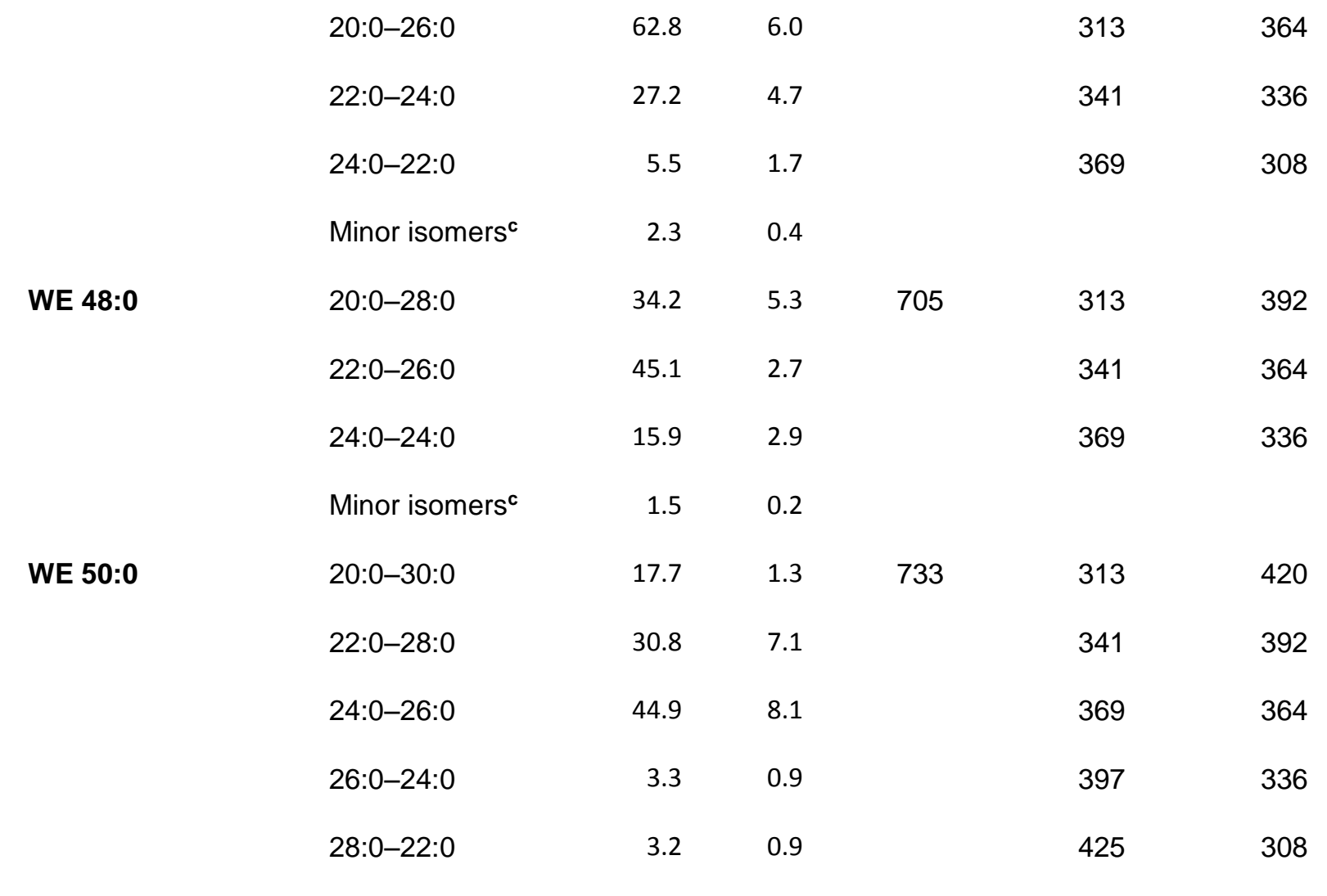

${ }^{\mathrm{a}} \mathrm{CN}$, carbon number of wax ester; DB, number of double bonds.

b The percentage of a single isomer of a saturated wax ester was calculated based on intensities of the $[\mathrm{RCO} 2 \mathrm{H} 2]^{+}$ion from 4 biological replicates.

c Wax ester isomers constituting less than $1 \%$ of the mixture were pooled and included in the "minor isomers" category. 


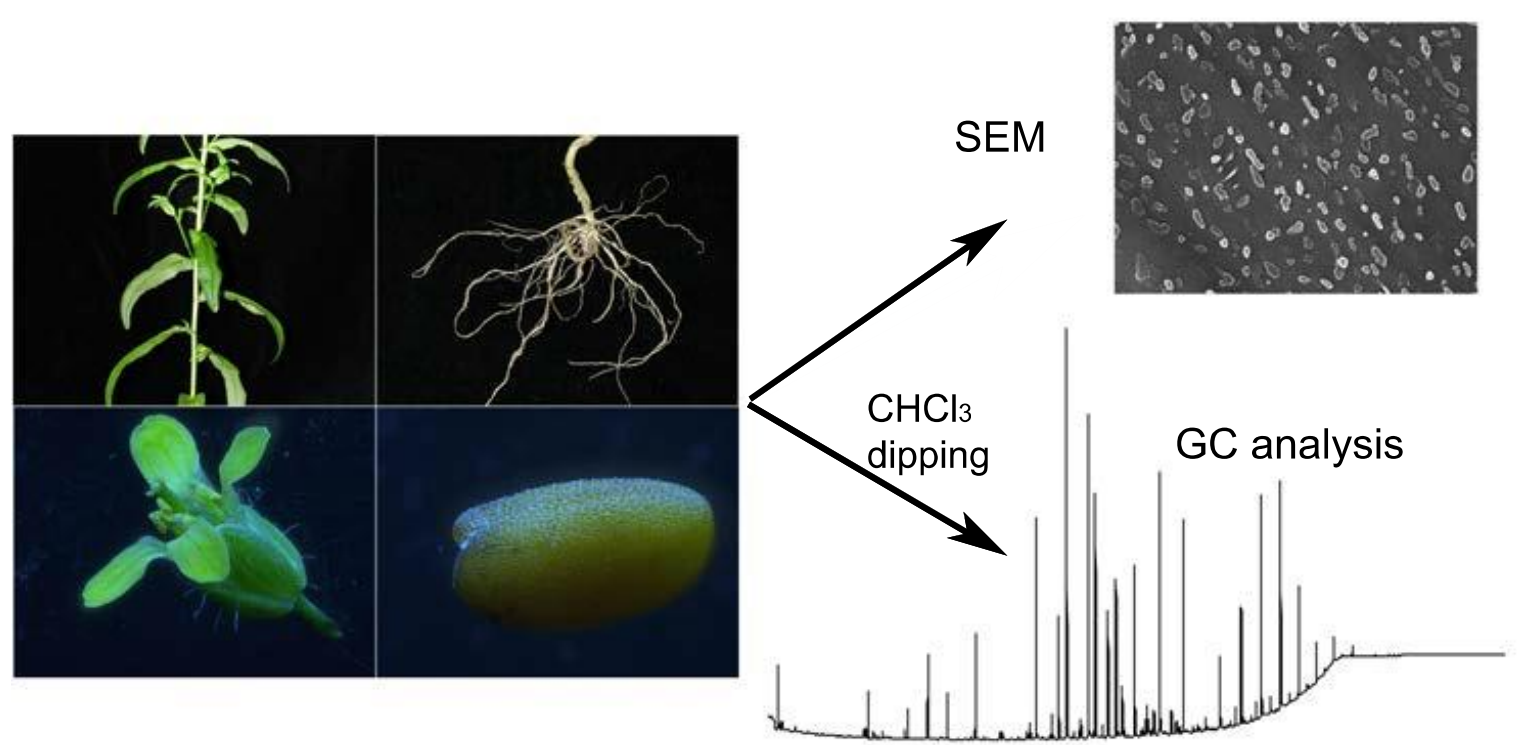

Analyses of chloroform-extractable waxes of Camelina sativa's aerial and subterranean surfaces show both overlapping and distinctive chemical compositions within the same species. 